\title{
APPLICATION OF MARK-RECAPTURE MODELS TO ESTIMATION OF THE POPULATION SIZE OF PLANTS
}

\author{
H. M. Alexander, ${ }^{1}$ N. A. Slade, ${ }^{2}$ And W. D. Kettle ${ }^{3}$ \\ ${ }^{1}$ Departments of Botany and Systematics and Ecology, University of Kansas, Lawrence, Kansas 66045 USA \\ ${ }^{2}$ Department of Systematics and Ecology and Natural History Museum, University of Kansas, \\ Lawrence, Kansas 66045 USA \\ ${ }^{3}$ Experimental and Applied Ecology Program, University of Kansas, Lawrence, Kansas 66045 USA
}

\begin{abstract}
Mark-recapture models have been widely used in ecology to estimate population sizes of animals. In contrast, estimation of plant population size has usually been assumed to be much easier. However, detection of individuals is difficult for perennial plants, such as the rare prairie plant Mead's milkweed (Asclepias meadii), which does not produce aboveground parts every year and lives in dense vegetation where nonflowering stems are hard to observe. In these cases, a count of the number of plants observed in a particular year may greatly underestimate the true population size, just as a count of animals in traps does not adequately estimate the total number of animals in an area. Using a family of closed population models (CAPTURE), we applied mark-recapture methodology to estimate population size of $A$. meadii. Over a 4-yr period, a total of 129 patches (aggregated collections of stems) was observed, with 124 flowering in at least one year. In any one year, however, the number of flowering patches ranged from 15 to 105 . Using model $\mathbf{M}_{\text {th }}$ of CAPTURE with these data, the estimated number of patches capable of flowering was 219. Although the confidence interval is broad (95\% confidence interval of 175-302), these results emphasize that the observed number of patches in any one year, or even over a 4-yr period, underestimates the actual population size.
\end{abstract}

Key words: Asclepias meadii; CAPTURE computer program; mark-recapture; milkweed; population size; prairie.

\section{INTRODUCTION}

In the preface to his now classic book, Population Biology of Plants, Harper (1977) compared the feasibility of studying the population biology of plants and animals and stated that "In many ways plants make better material for the study of populations-plants stand still to be counted and do not have to be trapped, shot, chased, or estimated." For many plant and animal species, this statement is clearly true. The sessile nature of plants makes it easier to count all individuals in an area, whereas animals must be captured and marked just to recognize those that have been counted, while realizing that marked animals are only part of the extant population. However, not all plant species are easy to census completely, so that population size based only on the counted plants is an underestimate of the true population size. Counts of plants based only on aboveground structures may underestimate total population size of species with a persistent seed bank (Leck et al. 1989) or of long-lived perennials that do not produce aboveground parts each year (Hutchings 1987, Mehrhoff 1989). In other cases, plants do not produce apparent flowers in every year; if the vegetation surrounding the plant is dense, as in a prairie, nonflow-

Manuscript received 12 February 1996; revised 6 August 1996; accepted 9 August 1996. ering plants may be difficult to find even though they are present.

The conceptual problem of estimating population size from partial censuses has been a subject of considerable work in studies of animal (including human) populations (Petersen 1896, Lincoln 1930, Jolly 1965, Seber 1965, Otis et al. 1978, Pollock et al. 1990). Although a diverse array of estimation methods has been developed, many share a basic methodological approach: a sample is captured and marked. Later, an additional sample(s) is taken and the probability of capture is estimated and used to extrapolate from the number of animals actually captured to the size of the entire population (Nichols 1992). If the proportion of marked individuals that is recaptured is low, then probability of capture is inferred to be low and the actual population size is inferred to be much larger than the marked sample. If later censuses consist mostly of recaptured individuals, the population size is estimated to be nearly equal to the number of marked animals. In essence, mark-recapture methods allow one to estimate the number of individuals that are present but never observed; thus the estimated population size generally will be larger (sometimes considerably) than the actual number of animals captured. Currently, two classes of models are commonly used: models such as Jolly-Seber (Jolly 1965, Seber 1965) that assume open populations in which organisms are added or lost in 
the interval between samples, and models such as Lincoln-Petersen (Petersen 1896, Lincoln 1930) and the family of models (Otis et al. 1978) in computer program CAPTURE (Rexstad and Burnham 1991), which assume closed populations in which the population is constant during the census interval.

As part of a study of the natural history of the Mead's milkweed (Asclepias meadii), we conducted censuses in a native prairie in each of four consecutive years. Two characteristics of the plant and these censuses suggested that models for estimating the size of populations, and in particular closed population models, might be appropriate for our data. First, despite intensive searches each year, we suspected that we were not detecting all plants. This incomplete census was likely to occur for two reasons: (a) plants without aboveground parts would be missed and (b) even when aboveground parts were present, plants were unlikely to be detected unless they flowered because of the dense prairie vegetation. Second, populations were likely to be "closed" (i.e., mortality and recruitment rates were likely to be negligible) for censuses taken over a 4-yr period because plants live for many decades (Betz 1989) and reproduction is very low at our study site $(\mathrm{H}$. M. Alexander, W. D. Kettle, and G. L. Pittman, unpublished manuscript). Our objective was to apply a closed population model to census data on this long-lived plant. We chose to use program CAPTURE (Rexstad and Burnham 1991) because it allowed us to fit several models to our data and to test for variation in probabilities of plants being observed (=captured).

\section{Methods}

\section{Study organism}

Asclepias meadii Torr. ex A. Gray, the Mead's milkweed, is a long-lived clonal perennial native to tallgrass prairies in the central United States. Betz (1989) observed individual plants for up to $25 \mathrm{yr}$ and suggested they may live for a century or longer. Flowering and nonflowering stems are produced in early summer from an underground system of shallow, slender rhizomes (Great Plains Flora Association 1986). The flowering stems have a pale-green inflorescence with fruits maturing in early fall (Plate 1, top). Nonflowering stems are slender with fewer than 12 leaves and are hard to detect in dense prairie vegetation (Plate 1, bottom). Prairie fires have a positive effect on the plants: Bowles et al. (1995) observed greater survivorship and growth of transplanted juveniles in response to fire and we found greater number of flowering stems of $A$. meadii in years when the prairie was burned in the spring $(\mathrm{H}$. M. Alexander, W. D. Kettle, and G. L. Pittman, unpublished manuscript). The number of populations and range of $A$. meadii have been reduced with the loss of prairie habitat. In 1988, the species was listed as a threatened species under the Endangered Species Act
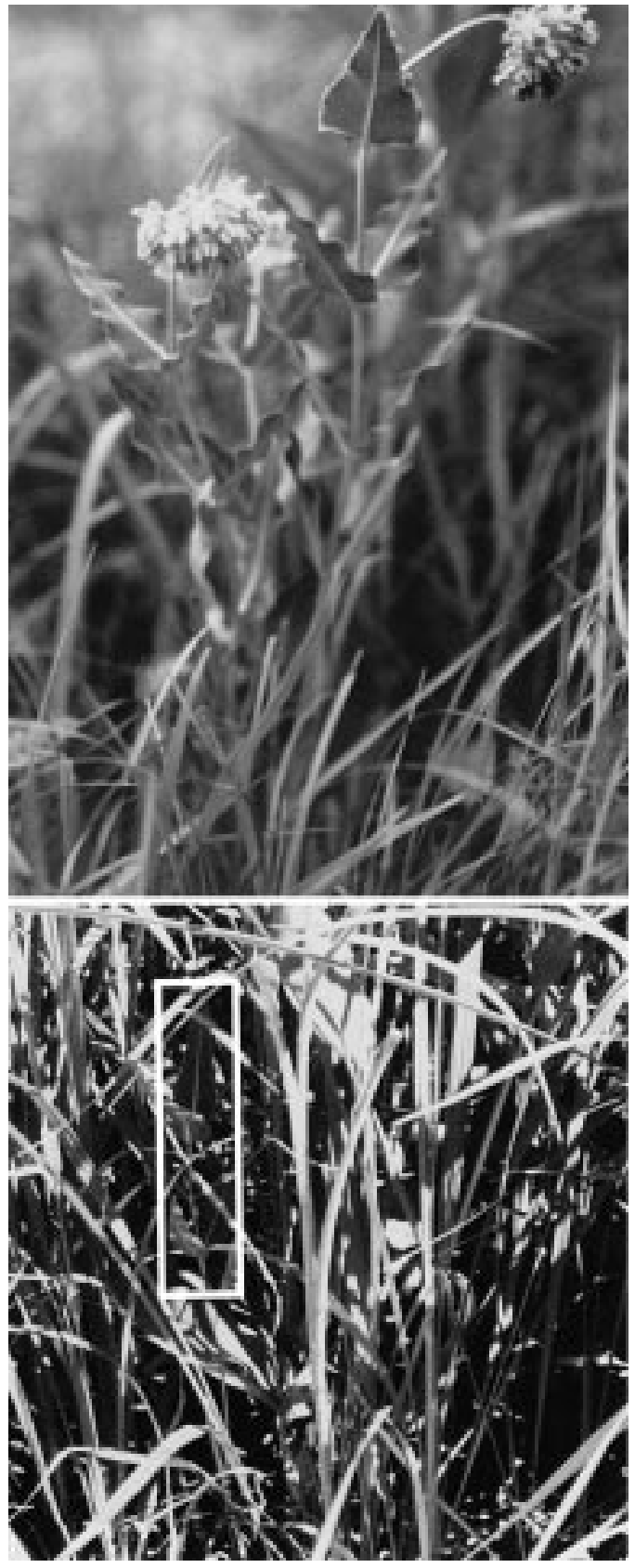

Plate. 1. Top: Flowering stems of A. meadii. Bottom: Nonflowering stem of $A$. meadii (inside rectangular outline); such stems are difficult to find in the prairie vegetation.

(Department of the Interior, U.S. Fish and Wildlife Service 1988).

\section{Study site and monitoring program}

We have studied a population of $A$. meadii on a 4.5-ha tract located on the Kansas Ecological Reserves managed by the University of Kansas (12 km northeast of Lawrence, Kansas) since 1988 (H. M. Alexander, W. D. Kettle, and G. L. Pittman, unpublished manu- 
script). The population is primarily on the Rockefeller Native Prairie, a 4-ha area; two patches of $A$. meadii (see definition below) are located within $17 \mathrm{~m}$ of the prairie in an adjacent formerly cultivated field that was sown to prairie grasses in 1957 . The native prairie has never been plowed and this prairie and reseeded tract have been managed largely by burning every 1-3 yr since 1957 (Fitch and Hall 1978) with burning in even numbered years since 1986. Burning occurs in the spring, prior to aboveground growth of $A$. meadii. This study focuses on data collected in 1992-1995, when the location of each flowering and nonflowering stem was flagged in the field and mapped. Stems are found each year by two surveys conducted during peak flowering in early June: (a) a systematic search of the entire prairie and (b) a more focused survey of known locations of stems in earlier years. For the latter, approximate locations of stems observed in the 19881991 period were searched in 1992, and stems that were found were marked with flags. In subsequent years, all flagged locations were revisited. Additionally, a small number of stems (yearly average of 4\%) was found later in the season by chance encounters.

For a clonal perennial plant, counts of individual stems (ramets) can be misleading since there are variable numbers of stems per plant. Our goal instead was to enumerate individual plants (genets). At the field site, stems were clearly spatially aggregated. We assigned individual stems to "patches" by grouping all 1992-1995 stems that were within $1.25 \mathrm{~m}$ of each other to the same patch. The choice of $1.25 \mathrm{~m}$ was largely arbitrary, although rhizomes up to $1 \mathrm{~m}$ long are known (M. L. Bowles, personal communication). The maximum span of a patch never exceeded $1.7 \mathrm{~m}$; patches were usually separated by several meters. Limited genetic data available, provided by M. L. Bowles and B. Schaal, were largely consistent with this patch definition (H. M. Alexander, W. D. Kettle, and G. L. Pittman, unpublished manuscript). Occasionally more than one genotype was found per patch, presumably due to establishment of a seedling within the "mother" patch.

\section{Description and application of CAPTURE models}

In our analyses, we assumed that the plant population was constant over the 4-yr period, i.e., that deaths (as well as births) did not occur. This assumption was based on the known multidecade life-span of the species (Betz 1989), our estimates of high survival rates for individual patches (yearly survival rate of 0.96 ; see Results), and the low fruit production we observed (in most years, fewer than four fruits matured at the site) (H. M. Alexander, W. D. Kettle, and G. L. Pittman, unpublished manuscript). Note that our assumption of constant population size is restricted to the 4-yr sampling period: the population may change in size over the long term, but we believe that births and deaths are negligible for a particular 4-yr period.

Our assumption of a constant population size over the 4 yr led us to explore closed mark-recapture models. The most familiar closed model is the LincolnPetersen approach (Pollock et al. 1990), where all captured individuals are marked on one date and the proportion of marked individuals that are recovered on a second date is used to estimate population size. In many animal applications and in our study, however, individuals are censused on more than two occasions and thus there are several dates at which marks are applied. Data from $t$ multiple censuses can be summarized in "capture histories," where each individual is represented by a row of $t$ binary digits, in which 0 indicates absence of an individual (i.e., failure to be observed) at a census and 1 indicates presence (Nichols 1992). Estimates of $N$ can be obtained from multiple censuses with Schnabel's (1938) extension of the Lincoln-Petersen approach. However, estimates of $N$ also can be obtained using a family of models (program CAPTURE; Rexstad and Burnham 1991) that incorporate several sources of variability in probability of capture. First, the probability of capture may vary over time (e.g., due to capture probability changing with weather). Second, individual behavior may change in response to being captured: marked individuals may either be more ("trap-happy") or less ("trap-shy") likely to be captured than individuals that have never been captured before. Finally, CAPTURE can account for heterogeneity in probability of capture among individuals, such that some individuals are always more or less likely to be captured than others (e.g., traps may be placed close or far from individuals' burrows).

With the assumption of a constant population size, a known patch of $A$. meadii could in theory have three possible states in any year: (1) at least one flowering stem present, (2) only nonflowering stem(s) present, or (3) no aboveground parts; only rhizomes present. We first constructed capture histories for individual patches by defining patch presence as the presence of either flowering or nonflowering stems and patch absence as the lack of any detected stems. The CAPTURE model uses these capture histories to estimate total population size (total number of patches). Prior to performing the analyses, we predicted that temporal variation in probability of detection was likely since there was strong year-to-year variation in production of flowering stems that, in part, appears to be associated with the spring burning of the prairie (H. M. Alexander, W. D. Kettle, and G. L. Pittman, unpublished manuscript). We also predicted, a priori, that a "behavioral" effect would occur since once a patch is observed (and permanently marked with a flag), it is relatively easy to find the nonshowy vegetative plants in subsequent years, whereas similar detection without marking is very difficult. Finally, our a priori prediction was that individual heterogeneity in capture would exist with A. meadii, since patches with large underground rhizome systems might produce flowering stems every year and have a high probability of detection, while patches with lower 
reserves may flower irregularly and thus have a low probability of detection.

Because of these three causes of variation in probability of detection, we predicted the best fit for our patch data would be CAPTURE model $\mathrm{M}_{\mathrm{tbh}}$, with subscripts indicating presence of temporal $(\mathrm{t})$, behavioral (b), and individual heterogeneities (h) in capture. However, simple estimators of population size do not exist for this complex model (Otis et al. 1978, Rexstad and Burnham 1991, but see Lee and Chao 1994). Our solution was to also run the model with an altered data set of capture histories where we attempted to eliminate one of the sources of variability in capture. In this "flowering" data set, we constructed capture histories such that a patch had a value of 1 (was captured) only if a flowering stem(s) was present; if we found no stems or only nonflowering stems, the patch was given a value of 0 . We predicted that the "behavioral" effect would not be present with analyses of the flowering data set, since flowering stems are apparent and could be detected whether the patch was or was not permanently marked in the field. Thus, our a priori prediction was that the model $\mathrm{M}_{\mathrm{th}}$ would provide the best fit for the flowering data set; estimators for $N$ are available for this model (Chao et al. 1992). This manipulation of data sets was done solely so that an estimate of population size could be obtained; for both data sets, our goal was to estimate the number of mature patches of A. meadii that were capable of flowering, and thus being detected.

We subsequently ran program CAPTURE (Version 6/92) on both the total data set and the flowering data set, requesting selection of an appropriate model and estimation of population size and probability of capture for the appropriate model (Rexstad and Burnham 1991). Additionally, since the model selection procedure of CAPTURE has been criticized when applied to only four capture occasions (Menkens and Anderson 1988), we requested estimates of population size and probability of capture for two specific models: the Chao estimator for model $\mathbf{M}_{\mathrm{th}}$ for the flowering data set (as described above) and interpolated jackknife estimates for model $\mathrm{M}_{\mathrm{h}}$ (Burnham and Overton 1979) because this model is reasonably robust and an estimator can be calculated for small data sets. We additionally estimated population size using another closed model by dividing the flowering data set into two groups (patches present in 1992-1993 vs. 1994-1995) and calculating a Lincoln-Petersen estimate of number of patches (Menkens and Anderson 1988).

The assumption of a closed population was assessed in two ways. First, the hypothesis of population closure was tested using the method of Otis et al. (1978) within program CAPTURE. This test of closure assumes the $\mathrm{M}_{\mathrm{h}}$ model (i.e., variation in capture due to heterogeneity among individuals). Second, we used Jolly-Seber (Jolly 1965, Seber 1965) analysis (program JOLLY version 2/24/89, Model A) on the total data set to estimate
TABLE 1. Frequency of Asclepias meadii patches with different capture histories. A "capture history" is a row with a number for each of the four years from 1992 to 1995. For the total data set, a " 1 ", indicates that flowering or nonflowering stems were observed in a particular year, while a " 0 "' indicates that no stems were detected. For the flowering data set, a " 1 ", is recorded only if we observed at least one flowering stem, while a " 0 " 'refers to situations where either no stems were detected or only nonflowering stems were found.

\begin{tabular}{ccc}
\hline \hline Capture history & Total data set & Flowering data set \\
\hline 0000 & 0 & 5 \\
1000 & 3 & 13 \\
0100 & 0 & 1 \\
0010 & 14 & 50 \\
0001 & 5 & 4 \\
1100 & 1 & 0 \\
1010 & 2 & 13 \\
1001 & 0 & 1 \\
0110 & 0 & 6 \\
0101 & 0 & 0 \\
0011 & 53 & 16 \\
1110 & 3 & 4 \\
1101 & 3 & 0 \\
1011 & 7 & 12 \\
0111 & 12 & 3 \\
1111 & 26 & 1 \\
Total & 129 & 129 \\
\hline
\end{tabular}

survival probabilities of the patches. The survival probability, $\phi$, is calculated using only the fate of marked individuals and is robust to variation in probabilities of capture (Pollock et al. 1990). A high estimated survival probability would be consistent with closure.

\section{RESULTS}

A total of 129 different patches were observed over the $4 \mathrm{yr}$, with 124 of these producing flowers in at least one year. In any one year, considerably fewer patches were detected (total numbers of patches, with number of flowering patches in brackets, were 45 [44], 45 [15], 117 [105], and 106 [37] for years 1992-1995). The frequencies of different capture histories for the total and flowering data sets are shown in Table 1. Using the total data set, the $\mathbf{M}_{\text {tbh }}$ model was chosen as the best fit and no other models seemed appropriate (model selection criteria $<0.6$ in program CAPTURE, Otis et al. 1978). The hypothesis of closure was rejected ( $z=$ $-5.179, P<0.0001)$, but the test of closure is not reliable in the presence of "behavioral" effects (Otis et al. 1978). With this total data set, the average yearly probability of survival of a patch was 0.963 using the JOLLY program (95\% confidence interval of $0.922-$ $1.004)$, which is consistent with the hypothesis of no deaths in the population. Using the flowering data set, the closure hypothesis was tenable $(z=-0.7, P=$ 0.24). The $M_{t h}$ model had the best fit (model selection criterion of 1). All but one other model had a model selection criterion $<0.65$ (Otis et al. 1978); we subsequently ran model $\mathrm{M}_{\mathrm{tb}}$ since it had a model selection criterion of 0.79 . With the Chao estimator for $M_{t h}$, the 
estimate of total population size was 219 patches with a standard error of 31.5 and a $95 \%$ confidence interval of 175-302. Estimated probabilities of capture were $0.20,0.07,0.48$, and 0.17 in 1992-1995, respectively. Using $\mathbf{M}_{\mathrm{h}}$, the interpolated population estimate ( $\pm 1 \mathrm{SE}$ ) was $203 \pm 15.8$ patches with a $95 \%$ confidence interval of 178-240; the average probability of capture for the 4 yr was 0.25 . The estimate ( $\pm 1 \mathrm{SE}$ ) from the $\mathrm{M}_{\mathrm{tb}}$ model was $139 \pm 9.4$ patches, with a $95 \%$ confidence interval of $129-170$.

Our CAPTURE analyses were based on all our data, i.e., patches found during the regular early summer census as well as the few patches that were found later in the summer. The advantage of this approach is that we used our total knowledge of the population; however a potential problem is that patches missed in the regular census may have certain attributes that alter their subsequent flowering behavior and thus capture probabilities. We explored this problem in two ways. First, we used an extension of Fisher's exact test to test the hypothesis that the three patches found late in the summer in 1992 had subsequent flowering capture histories in 1993-1995 similar to the total 1992 population of patches. Our results were consistent with this hypothesis $(P=0.69)$. We additionally performed analyses on the flowering data set where we only included a patch if it was observed during the regular census in 1992-1995; eight patches were therefore eliminated from the data set. Model $\mathrm{M}_{\mathrm{th}}$ was again the best model with this data set, yielding an estimated population size of 193 (95\% confidence interval of $155-266)$. We reduced our data set by $6.5 \%(8 / 124)$; our population estimate was reduced by a roughly comparable amount of $11.9 \%(26 / 219)$.

The Lincoln-Peterson estimate of population size from the flowering data set was 149 with a standard error of 2.9 .

\section{Discussion}

\section{Estimation of population size of $\mathrm{A}$. meadii}

We observed 129 total patches (124 known to flower) over the 4-yr period. Assuming that no births or deaths occurred over this period, this "count" of observed patches is the typical plant biologist's estimate of population size. Although a reasonable minimum estimate, this count of observed individuals shares the same problem of all "enumeration" techniques used with animal populations (e.g., minimum number known alive; Hilborn et al. 1976) in that actual population size is underestimated, sometimes severely (Nichols and Pollock 1983a) and there is no estimate of precision. Programs such as CAPTURE correct for this underestimate by estimating probabilities of capture and using them to infer the number of individuals that are not detected. Our CAPTURE estimate using $\mathrm{M}_{\text {th }}$ has a coefficient of variation of $\approx 15 \%$; however, even the lower limit of the $95 \%$ confidence interval for this es- timate, 175 patches, is much larger than the observed total number of patches.

The model selection procedure of CAPTURE chose the $\mathrm{M}_{\mathrm{th}}$ model, with "temporal" and "individual heterogeneity" sources of variation in probability of capture. The biology of $A$. meadii is consistent with this result. Temporal variation in detection is obviousvery few patches flowered in 1993 while large numbers of patches flowered in 1994. Our data suggest that individuals do not respond identically to this temporal variation. This erratic flowering is critical to population size estimation since flowering is nearly essential for initially detecting the plants in the dense prairie vegetation. For example, 20 patches flowered in at least 3 of the $4 \mathrm{yr}$ (Table 1). In contrast, 66 flowering patches were observed for the first time in 1994 (Table 1), despite the fact that detailed yearly surveys had been conducted since 1988 . Further, the probability of capture (which is highly dependent on flowering patterns) was unusually high in 1994. Although the reasons for this peak flowering year are unknown, it is noteworthy that in the previous year there had been record levels of rainfall (summer rainfall more than twice the 133-yr average; Ward 1994:81) and the prairie was burned in spring 1994. Many vegetative plants may therefore persist on the prairie for years without detection, and only an unusual set of circumstances allows them to flower and thus be included in our surveys. Support for this assertion also comes from additional data sets. A less precise mapping technique was used in 1990, so that 1990 patches could not be exactly matched with our 1992-1995 patches. However, it is noteworthy that 36 of the 54 patches that flowered in 1990 (66.7\%) were at least $5 \mathrm{~m}$ from any patch found from 1992 to 1995 . Extensive clonal movement over this time period seems unlikely. Given the high survival rates inferred from the 1992-1995 data, many of the patches detected in 1990 are probably still present, but were not included in our count of 129 observed patches because they have not flowered again. Other researchers have also discussed the erratic behavior of A. meadii: Betz (1989) noted that rootstocks produced flowering stems for a number of years and then stopped producing stems or only produced very small stems for a few years. Given the importance of individual heterogeneity in probability of detection, it is not surprising that the estimates of population size using Lincoln-Petersen (which is analogous to CAPTURE model $\mathrm{M}_{t}$; Otis et al. 1978) or model $\mathrm{M}_{\mathrm{tb}}$ in CAPTURE differed from the estimates of population size that considered this source of variation in capture probability.

An alternate explanation of the capture histories is that the population is not truly closed over the 4-yr period, and that newly detected flowering patches in a particular year are new recruits to the population. Although certainly some recruitment may occur (for example, we know that the two patches in the reseeded area have appeared since 1957), we believe it is an 
unlikely explanation for most patches. Work by Betz (1989) has shown that greenhouse-reared plants take 5-7 yr to flower; thus any new flowering patches in the 1990s must result from fruit production in the 1980s. Although we lack data on reproduction in the 1980s, fruit production of Mead's milkweed at this site in the 1990s has been extremely low. With the exception of an unusual year (1994) when 41 mature fruits were found, fruit production for the entire population in 1992, 1993, and 1995 did not exceed four fruits per year (H. M. Alexander, W. D. Kettle, and G. L. Pittman, unpublished manuscript). It is likely that herbivory is a major factor at this site: in most years only $4 \%$ of the flowering stems produce mature fruit and clipped stems are common (H. M. Alexander, W. D. Kettle, and G. L. Pittman, unpublished manuscript). Given an average of 60 seeds per fruit (Betz 1989), yearly seed production is clearly low. Bowles et al. (1995) also report that only three seedlings survived $2 \mathrm{yr}$ following the sowing of 125 seeds at four sites in Indiana and Illinois. Since prereproductive mortality of seedlings in subsequent years is also likely to be high in the dense prairie, it is difficult to imagine years of high recruitment for this species.

Longer term data sets from our continuing observations will allow us to better quantify the patterns of survivorship and flowering for this species. Specifically, we will be able to explore whether the plants that flowered first in 1994 represent a subclass of plants that flower only infrequently. It will also be valuable to compare our estimates based on $4 \mathrm{yr}$ to estimates based on more years of data. Otis et al. (1978) recommend five or more sampling dates for CAPTURE analyses; however, there is a trade-off between more years of data and increased probability of violation of the "closure" assumption. As our data set grows through time, one possibility is to calculate estimates over different 5-yr intervals (i.e., 1992-1996, 1993 $1997,1994-1998, \ldots$ ) to explore the variance in the estimates and, ideally, determine whether there are long-term changes in population size.

\section{Mark-recapture models and plant population biology}

The application of mark-recapture models forces one to realize that the probability of detection of individual plants is not always $100 \%$. There are two major implications of this observation. First, the true population size will be larger than the number of plants actually observed, and, second, population size cannot be precisely known. Several aspects of applying mark-recapture approaches to plants are worth noting. For example, it is true that over time one should simply run out of new individuals to mark in a closed population and thus acquire a complete census. Simulation studies (N. A. Slade, unpublished data) illustrate that as one captures more and more of the individuals in a closed population, the population size estimated by CAPTURE approaches the actual population size. However, the population size calculated by CAPTURE provides a reasonable estimate of population size long before all individuals are actually detected in the simulated surveys. It is further clear that flagging plants increases the recapture probability: plants are "trap happy" and once marked, patches are likely to be detected again. However, the CAPTURE models specifically incorporate behavioral effects. For example, model $\mathrm{M}_{\mathrm{bh}}$ can estimate population size of animals censused by removal trapping (Woodman et al. 1995), where individuals are taken from the site after capture and thus are extremely "trap shy" (individuals are never detected more than once). The problem we initially faced was that all three sources of variation in capture probability $(\mathrm{t}, \mathrm{b}$, and $\mathrm{h}$ ) were needed; in an extreme case each organism would have a unique capture history and thus population size estimates are impossible because the number of parameters that must be estimated exceed the available data. We were able to largely eliminate the behavioral effect by focusing on flowering plants, and thus obtain a population size estimate. Another approach would be to partition the population into groups and use capture-recapture models of structured populations (Brownie et al. 1993).

It is reasonable to compare use of the mark-recapture model to an alternative approach of estimating population size through the cumulative number of plants found over a series of years. The same field data are needed for either method. The main advantages of mark-capture approaches are twofold. First, by analyzing the data with the mark-recapture models, one gains information on the degree of temporal heterogeneity and the presence or absence of behavioral factors and individual heterogeneity in detection of organisms. Second, and most importantly, the mark-recapture approach provides a more honest assessment about one's confidence in the population size estimate. If there is considerable variation in probability of capture due to different years or individual heterogeneity, for example, the CAPTURE approach forces one to realize that precise estimates of population size are not possible with any method.

Finally, how generally applicable is this method? How commonly will a simple count of plants lead to an underestimate of population size? Mehrhoff (1989) notes that $20 \%$ of the individuals of the orchid Isotria medeoloides that were recorded as "absent" in a growing season eventually produced aboveground parts and thus had been dormant. Similar results were found with the orchid Ophrys sphegodes, where individuals persisted underground for 1-2 or even 5 yr (Hutchings 1987). Clearly the majority of plant species do produce aboveground parts each year. However, the critical question is whether all individuals are likely to be detected each year. Our experience with the dense vegetation of tallgrass prairies suggests that counts of many perennial species are underestimates because 
vegetative individuals are easily missed unless very time-consuming, small spatial scale studies are done.

There are several conservation implications of the general phenomenon that the probability of detection (capture) of plants is $<100 \%$ for certain species and habitat types. The most obvious consequence is that determination of whether a species is "rare" or not may be difficult. For A. meadii there is no question that the number of populations has been greatly reduced since pre-European settlement. Many of the remaining populations also are undoubtedly small: for example, in Kansas, no more than 10 stems have been recorded at over one-third of the sites where $A$. meadii has been found (Kansas Natural Heritage Program, unpublished data). However, our results suggest that some populations may be much larger than previously thought. The difficulty is that the larger size is an estimate; Caughley and Sinclair (1994), for example, argue that management decisions for rare species should be based on a more conservative count of observed individuals than an estimated total population size. A second consequence is that given the large variance in estimated population size at any one time, it will be difficult to detect a downward or upward trend because of the low statistical power (Taylor and Gerrodette 1993). If there are important conservation consequences of missing a trend in declining population size, one may want to compensate for the reduced statistical power by increasing the alpha value above the traditional 0.05 level (e.g., 0.1 or 0.2 ). Even larger problems in estimating population size arise if, due to limited resources and time, individuals are not flagged or mapped in censuses. For example, 45 total patches were observed in both 1992 and 1993 at our site. Without mapping, one might conclude that the same patches were found each year, while in reality $12(26.7 \%)$ of the 1993 patches had not been observed in 1992. This general issue of problems of detection is not limited to population-level studies; Nilsson and Nilsson (1982) discussed how incomplete detection of plant species in community surveys can lead to false conclusions about extinction rates, and capture-recapture models have been used to estimate taxonomic diversity and extinction rates from fossil data (Nichols and Pollock 1983b, Nichols et al. $1986 a$ ). In fact, the related question of how to estimate number of species in a community given multiple samples can be addressed in a similar way using the $M_{h}$ model of CAPTURE (Burnham and Overton 1979).

Besides the typical use of mark-recapture methodology in estimation of animal population size, these approaches have other diverse biological and nonbiological applications (Nichols 1992). It is therefore not surprising that mark-recapture techniques also are relevant for the study of plants. Further, it is ironic that in some features, our plant data match the assumptions of the capture-recapture models better than real trapping data on animals. For example, the likelihood models of CAPTURE assume that multiple captures within a single trapping occasion are independent events (i.e., the probability of an individual being captured is not affected by capture of others). However, when several animals are exposed to the same single-capture trap, only one will be captured. Thus at high population densities relative to densities of traps, probabilities of capture for different animals are likely to be dependent. In contrast, visual surveys of plants do not involve modification of opportunities to be observed, with the possible exception that finding one plant may increase probability of detection of neighboring individuals. Thus, it is reasonable to assume that probabilities of being "captured" are largely independent. In this sense, plant surveys might be more related to line transect surveys of animals (Buckland et al. 1993); it is noteworthy that CAPTURE models have been applied to estimating numbers and probability of detection from transect surveys of other sessile objects such as bird nests (Nichols et al. 1986b).

\section{ACKNOWLEDGMENTS}

We thank G. Pittman, B. Johanning, J. Campbell, G. Ward, K. Kindscher, A. McMillan, and T. Daugherty for their assistance in censuses and The Experimental and Applied Ecology Program of the University of Kansas for financial support. M. Bowles, C. Freeman, K. Kindscher, and R. McGregor provided useful information about $A$. meadii and J. Nichols provided references on unusual applications of mark-recapture techniques. Comments by J. Nichols and those of an anonymous reviewer improved the manuscript.

\section{Literature Cited}

Betz, R. F. 1989. Ecology of the Mead's milkweed (Asclepias meadii Torrey). Proceedings of the Eleventh North America Prairie Conference:187-191.

Bowles, M. L., J. L. McBride, and R. F. Betz. 1995. Mead's milkweed (Asclepias meadii) restoration in Illinois and Indiana. Report to U.S. Fish and Wildlife Service and U.S. Forest Service.

Brownie, C., J. E. Hines, J. D. Nichols, K. H. Pollock, and J. B. Hestbeck. 1993. Capture-recapture studies for multiple strata including non-Markovian transitions. Biometrics 49:1173-1187.

Buckland, S. T., D. R. Anderson, K. P. Burnham, and J. L. Laake. 1993. Distance sampling: estimating abundance of biological populations. First edition. Chapman and Hall, London, England.

Burnham, K. P., and W. S. Overton. 1979. Robust estimation of population size when capture probabilities vary among animals. Ecology 60:927-936.

Caughley, G., and A. R. E. Sinclair. 1994. Wildlife ecology and management. Blackwell Scientific, Boston, Massachusetts, USA.

Chao, A., S. M. Lee, and S. L. Jeng. 1992. Estimating population size for capture-recapture data when capture probabilities vary by time and individual animal. Biometrics 48:201-216.

Department of the Interior, U.S. Fish and Wildlife Service. 1988. Endangered and threatened wildlife and plants; determination of threatened status for Asclepias meadii (Mead's milkweed). Federal Register 53:33992-33995.

Fitch, H. S., and E. R. Hall. 1978. A 20-year record of succession on reseeded fields of tallgrass prairie on the Rockefeller Experimental Tract. University of Kansas Publications, Museum of Natural History 4:1-15.

Great Plains Flora Association. 1986. Flora of the Great 
Plains. University Press of Kansas, Lawrence, Kansas, USA.

Harper, J. L. 1977. Population biology of plants. Academic Press, New York, New York, USA.

Hilborn, R., J. A. Redfield, and C. J. Krebs. 1976. On the reliability of enumeration for mark and recapture census of voles. Canadian Journal of Zoology 54:1019-1024.

Hutchings, M. J. 1987. The population biology of the early spider orchid, Ophrys sphegodes Mill. I. A demographic study from 1975 to 1984 . Journal of Ecology 75:711-727.

Jolly, G. M. 1965. Explicit estimates from capture-recapture data with both death and immigration-stochastic model. Biometrika 52:225-247.

Leck, M. A., V. T. Parker, and R. L. Simpson, editors. 1989. Ecology of soil seed banks. Academic Press, San Diego, California, USA.

Lee, S.-M., and A. Chao. 1994. Estimating population size via sample coverage for closed capture-recapture models. Biometrics 50:88-97.

Lincoln, F. C. 1930. Calculating waterfowl abundance on the basis of banding returns. United States Department of Agriculture Circular 118: $1-4$.

Mehrhoff, L. A. 1989. The dynamics of declining populations of an endangered orchid, Isotria medeoloides. Ecology 70:783-786.

Menkens, G. E., and S. H. Anderson. 1988. Estimation of small-mammal population size. Ecology 69:1952-1959.

Nichols, J. D. 1992. Capture-recapture models. BioScience 42:94-102.

Nichols, J. D., R. W. Morris, C. Brownie, and K. H. Pollock. 1986a. Sources of variation in extinction rates, turnover, and diversity of marine invertebrate families during the Paleozoic. Paleobiology 12:421-432.

Nichols, J. D., and K. H. Pollock. 1983a. Estimation methodology in contemporary small mammal capture-recapture studies. Journal of Mammalogy 64:253-260.

Nichols, J. D., and K. H. Pollock. 1983b. Estimating taxo- nomic diversity, extinction rates, and speciation rates from fossil data using capture-recapture models. Paleobiology 9 : 150-163.

Nichols, J. D., R. E. Tomlinson, and G. Waggerman. $1986 b$. Estimating nest detection probabilities for white-winged dove nest transects in Tamaulipas, Mexico. Auk 103:825828.

Nilsson, I. N., and S. G. Nilsson. 1982. Turnover of vascular plant species on small islands in Lake Mockeln, South Sweden 1976-1980. Oecologia 53:128-133.

Otis, D. L., K. P. Burnham, G. C. White, and D. R. Anderson. 1978. Statistical inference from capture data on closed animal populations. Wildlife Monographs 62:1-135.

Petersen, C. G. J. 1896. The yearly immigration of young plaice into the Limfjord from the German Sea. Report of the Danish Biological Station 6:1-48.

Pollock, K. H., J. D. Nichols, C. Brownie, and J. E. Hines. 1990. Statistical inference for capture-recapture experiments. Wildlife Monographs 107:1-97.

Rexstad, E., and K. P. Burnham. 1991. User's guide for interactive program CAPTURE: abundance estimation of closed animal populations. Colorado Cooperative Fish and Wildlife Research Unit, Fort Collins, Colorado, USA.

Schnabel, Z. E. 1938. The estimation of the total fish population of a lake. American Mathematical Monthly 45:348352.

Seber, G. A. F. 1965. A note on the multiple-recapture census. Biometrika 52:249-259.

Taylor, B. L., and T. Gerrodette. 1993. The uses of statistical power in conservation biology: the vaquita and northern spotted owl. Conservation Biology 7:489-500.

Ward, G. C. 1994. Ecology of Tomanthera auriculata, a rare plant. Master's thesis, University of Kansas, Lawrence, Kansas, USA.

Woodman, N., N. A. Slade, R. M. Timm, and C. A. Schmidt. 1995. Mammalian community structure in lowland, tropical Peru, as determined by removal trapping. Zoological Journal of the Linnean Society 113:1-20. 